Tropical Journal of Pharmaceutical Research January 2017; 16 (1): 225-230

ISSN: $1596-5996$ (print); 1596-9827 (electronic)

(C) Pharmacotherapy Group, Faculty of Pharmacy, University of Benin, Benin City, 300001 Nigeria.

All rights reserved.

Available online at http://www.tjpr.org

Original Research Article

http://dx.doi.org/10.4314/tjpr.v16i1.30

\title{
Expressions of Wingless and Int 1 (Wnt)-induced secreted protein 1 in paraquat-poisoned patients
}

\author{
Jing-yan Liu ${ }^{1,2}$, Yu-juan Guo ${ }^{2}$, Yong-zhan Song ${ }^{3}$, Xing-liang Song ${ }^{4}$ and Dian-jie \\ $\operatorname{Lin}^{1 *}$ \\ ${ }^{1}$ Department of Pneumology, Shandong Provincial Hospital Affiliated to Shandong University, Jinan 250021, ${ }^{2}$ Department of \\ Emergency, Linyi People's Hospital, Linyi 276000, ${ }^{3}$ Digestive Department, Chinese Medicine Hospital in Linyi City, Linyi \\ $276003,{ }^{4}$ School of Chemistry \& Chemical Engineering, Linyi University, Linyi 276000, PR China
}

*For correspondence: Email: lindjsd@126.com; Tel/Fax: +86-0531-87938911

Received: 30 September 2016

Revised accepted: 21 December 2016

\begin{abstract}
Purpose: To study the expression of Wingless \& Int1 (Wnt)-induced secreted protein 1 (WISP1) in paraquat $(P Q)$-poisoned patients.

Methods: A total of 37 PQ-poisoned patients were enrolled in the study, and divided into non-survivor group (NS) and survival group (S) based on the final therapeutic outcome. Besides, another normal control group (NC) comprised of normal healthy people. Serum PQ concentration was determined by high performance liquid chromatography (HPLC), while reverse transcription-polymerase chain reaction (RT-PCR) and enzyme-linked immunosorbent assay (ELISA) were used to evaluate WISP1 in the serum of $P Q$ poisoned patients.

Results: $P Q$ intake in NS and $S$ groups were $23.58 \pm 26.23$ and $143.18 \pm 263.04 \mathrm{~mL}$, respectively, while serum $P Q$ concentration was $2.07 \pm 0.67$ and $4.12 \pm 1.74 \mathrm{mg} / \mathrm{L}$, respectively. Significant correlation was found between the outcome of patients and serum $P Q$ concentration $(O R=1.434, p<$ 0.01). Serum $P Q$ concentration was closely correlated with WISP1 gene expression levels $(O R=0.621$, $p<0.01)$ and serum WISP1 protein levels $(O R=0.596, p<0.01)$ on the first day after poisoning. Furthermore, a correlation between serum $P Q$ concentration and WISP1 levels was found on the third after poisoning $(O R=0.447, p<0.01)$.

Conclusion: WISP1 is over-expressed in PQ-poisoned patients, and serum $P Q$ concentration may be a useful index for the prognosis of $P Q$ poisoned patients.
\end{abstract}

Keywords: Wingless \& Int1 (Wnt)-induced secreted protein 1, Poison, Paraquat, Prognosis, Correlation

Tropical Journal of Pharmaceutical Research is indexed by Science Citation Index (SciSearch), Scopus, International Pharmaceutical Abstract, Chemical Abstracts, Embase, Index Copernicus, EBSCO, African Index Medicus, JournalSeek, Journal Citation Reports/Science Edition, Directory of Open Access Journals (DOAJ), African Journal Online, Bioline International, Open-J-Gate and Pharmacy Abstracts

\section{INTRODUCTION}

Paraquat (PQ), also named as 1,1-dimethyl-4,4bipyridinium dichloride, is commonly used as a non-selective herbicide. However, PQ can result in acute poisoning via intake through digestive tract and mucous membrane. Currently, it's reported that $\mathrm{PQ}$ poisoning has a very high morbidity ranging from 30.0 to $88.89 \%$ [1-3]. PQ could lead to the over-releases of many cytokines in $\mathrm{PQ}$ poisoned animal and humans.
Wingless \& Int 1 (Wnt)-induced secreted protein 1 (WISP1), a matricellular protein of CCN family, regulates proliferation, survival and migration of cells. Furthermore, WISP1 plays an important effect on wound repair, tumorigenesis and angiogenesis [4-6]. It is reported that WISP1 is a mediator of disturbed epithelial-mesenchymal crosstalk. WISP1 could be up-regulated in experimental lung fibrosis and could promote the development of pulmonary fibrosis in vivo [7]. WISP1 was also up-regulated in alveolar 
epithelial type II cells with stretch-induced epithelial-mesenchymal transition (EMT) in vitro [8], and related to ventilator-induced lung injury models in vivo [9].

The previous reports indicate that WISP1 plays a crucial role in pulmonary injury and fibrosis. Thus, we hypothesize that WISP1 may play an important role in the development of pulmonary injury and fibrosis induced by $P Q$. However, expression changes of WISP1 in $\mathrm{PQ}$ poisoned patients have not been reported so far. This study was designed to investigate WISP1 expression in serum of $P Q$-poisoned patients and explore the relationship between $P Q$ concentration and WISP1 levels in PQ-poisoned patients.

\section{METHODS}

\section{Subjects}

The $20 \% \mathrm{PQ}(\mathrm{w} / \mathrm{v})$ poisoned patients were collected in Linyi Peoples's Hospital (Linyi, China) from Jan. 2013 to Jun. 2014. The PQ intake ranges of these patients were from one mouthful to $20 \mathrm{~mL}$. The patients were divided into non-survivor (NS) and survivor (S) groups according to the final therapeutic outcome. Besides, another normal control group (NC) was also set by normal healthy volunteers. Twenty female and 17 male PQ-poisoned patients with a mean age of 30 years (ranging from 20 to 59 years old) were enrolled in the study. The protocols of this study were approved by the Ethics Committee of the Linyi Peoples's Hospital (approval no. 2013-J-03) and in accordance with the Helsinki declaration [10]. The written consent of all subjects and their relatives was obtained.

\section{Blood sample collection}

Venous blood samples $(6 \mathrm{~mL})$ were collected in vacuum blood collection tube from each $P Q$ poisoned patient on the first and third days in the hospital. Healthy control participants' venous blood samples were collected in the morning. The blood samples were centrifuged (3000 g, for $10 \mathrm{~min}$ ) and the serum samples were collected and kept at $-80^{\circ} \mathrm{C}$ until assays.

\section{Determination of $P Q$ in serum}

An Agilent Zorbax HC-C 18 (2.1 mm $\times 150 \mathrm{~mm}, 5$ $\mu \mathrm{m})$ column was applied for chromatographic analysis with temperature set at $30^{\circ} \mathrm{C}$. The flowrate of the mobile phase A (acetonitrile, $15 \%$ ) was set as $1.0 \mathrm{~mL} / \mathrm{min}$. Mobile phase $B$ contained $260 \mathrm{mM}$ sodium dihydrogen phosphate and $20 \mathrm{mM}$ sodium heptanesulfonate.
The $\mathrm{pH}$ was adjusted to 2.0 with triethylamine. The detection wavelength was $256 \mathrm{~nm}$ for PQ.

\section{Sample preparation}

A $400 \mu \mathrm{L}$ aliquot of patient's serum was added to $500 \mu \mathrm{L}$ of acetonitrile, and the mixture was mixed for $30 \mathrm{~s}$ in a vortex mixer. Then, the mixed sample was centrifuged (7000 $\mathrm{g}$, for $5 \mathrm{~min}$ ) to obtain the supernatants. After that, the supernatants were mixed with $3 \mathrm{~mL}$ trichloromethane $\left(\mathrm{CHCl}_{3}\right)$ and then mixed. Subsequently, the mixture was again centrifuged (7000 $\mathrm{g}$, for $5 \mathrm{~min}$ ). The lower colorless transparent liquid $(20 \mu \mathrm{L})$ was collected for the tests.

\section{Calibration curve}

Six calibration serum standards $(0.5,1.0,2.5$, $5.0,10.0$, and $100.0 \mu \mathrm{g} / \mathrm{mL}$ ) were prepared by spiking $400 \mu \mathrm{L}$ blank human serum with $600 \mu \mathrm{L}$ of the working solutions of $P Q$. After internal standard solution was added and deproteinization was performed, the serum mixture was introduced into the HPLC column, and $P Q$ levels were measured by the internal standard method.

\section{Total RNA extraction and cDNA preparation}

Total RNA was extracted using Trizol reagent (Sigma Alorich Co. LLC), and the RNA concentration was quantitated by spectrophotometry and agarose gel electrophoresis. The mixture of $1 \mu \mathrm{L}$ of total RNA and $13 \mu \mathrm{L}$ water was incubated at $65^{\circ} \mathrm{C}$ for 5 min. Then successively add $4 \mu \mathrm{L} 5 \times \mathrm{M}-\mathrm{MLV}$ buffer, $1 \mu \mathrm{L}$ of M-MLV RTase and $1 \mu \mathrm{L}$ of primer. The mixture was incubated at $37^{\circ} \mathrm{C}$ for $15 \mathrm{~min}$, and reverse transcriptase was performed by heating at $98{ }^{\circ} \mathrm{C}$ for $5 \mathrm{~min}$. Then, the cDNA was kept at $-20{ }^{\circ} \mathrm{C}$. Primer sequences for WISP-1 were obtained according to previous study [7]. Primers of GAPDH gene were designed according to the online ensemble database (http://www.ensembl.org). Primers used in this research were purchased from Invitrogen Life Co., Shanghai, China (Table 1).

\section{Reverse transcription-polymerase chain reaction (RT-PCR) assay}

Conditions for reverse transcription-polymerase chain reaction (RT-PCR) assays were optimized by using iCycler iQ (BioRad, USA). Hot start PCR was performed using a program of $5 \mathrm{~min}$ denaturation at $95^{\circ} \mathrm{C}$, followed by 35 cycles $(95$ ${ }^{\circ} \mathrm{C}$ for $30 \mathrm{~s}, 55^{\circ} \mathrm{C}$ for $20 \mathrm{~s}$, and $72{ }^{\circ} \mathrm{C}$ for $30 \mathrm{~s}$ ), and then a final 10 min extension at $72{ }^{\circ} \mathrm{C}$. Then 
$2 \mu \mathrm{L}$ cDNA was analyzed on $1.5 \%$ agarose gel. Gel imaging system (Universal Hood II) was used to take UV photography. The gel photograph result was analyzed by Gel-Pro Analyzer Version 3.0 gel image analysis system.

Table 1: Primers used for RT-PCR assay

\begin{tabular}{lll}
\hline Gene & & Sequence \\
\hline & Forwar & $5-$ \\
WISP1 & d & TGCTGTAAGATGTGCGCTCAG- \\
& & 5 \\
& Revers & GCTACCCCATGCGTTATCCTCA \\
& e & CA-3 \\
GADP & Forwar & $5-$ \\
H & d & 3 \\
& & GAGCGAGATCCCTCCAAAAT- \\
& Revers & - GGTACTCTTCATACTGTTGTCG \\
& e & G-3 \\
\hline
\end{tabular}

Enzyme-linked immunosorbent assay (ELISA)

WISP1 protein levels in the blood serum were determined by using commercial WISP-1 (CCN4) human enzyme-linked immunosorbent assay (ELISA) kit (Abcam, USA) according to the instructions described by the manufacturer.

\section{Statistical analysis}

Data were analyzed by SPSS 19.0 statistical software, and are presented as mean \pm standard deviation (SD). The $t$-test was used to investigate the differences among quantitative variables. The relationships between categorical variables and outcomes were evaluated using Spearman correlation, Chi square test and Logistics regression. In all cases, a confidence interval of $95 \%$ and a level of $p<0.05)$ were considered significant.

\section{RESULTS}

\section{Demography and mortality}

There were 37 patients $(20$ females and 17 males) collected in the study. The age and $P Q$ intake amount of $P Q$ poisoned patients' were $30.97 \pm 11.54$ years and $59.34 \pm 150.90 \mathrm{~mL}$, respectively. There were 11 patients in the nonsurvivor group (NS) and 26 patients in the survival group (S). There were $24 \mathrm{PQ}$-poisoned patients with multi-organ failure, especially acute kidney injury. Besides, 13 patients had acute lung injury and 9 patients died from acute respiratory failure.

\section{Serum $P Q$ concentration}

As shown in Table 2, the intake amount of $P Q$ of the $S$ and NS groups were $23.58 \pm 26.23 \mathrm{~mL}$ and $143.18 \pm 263.04 \mathrm{~mL}$, respectively. Furthermore, the serum contents of $P Q$ were determined by HPLC assay (Fig 1). The results were showed in Table 2 indicated that the serum contents of $P Q$ of the $S$ and NS patients were $2.07 \pm 0.67 \mathrm{mg} / \mathrm{L}$ and $4.12 \pm 1.74 \mathrm{mg} / \mathrm{L}$, respectively, which also represented an obvious difference $(p<0.01)$. There was no obvious relationship between $P Q$ intake amount and serum $P Q$ contents $(R R=$ $0.078, p=0.647$ ).

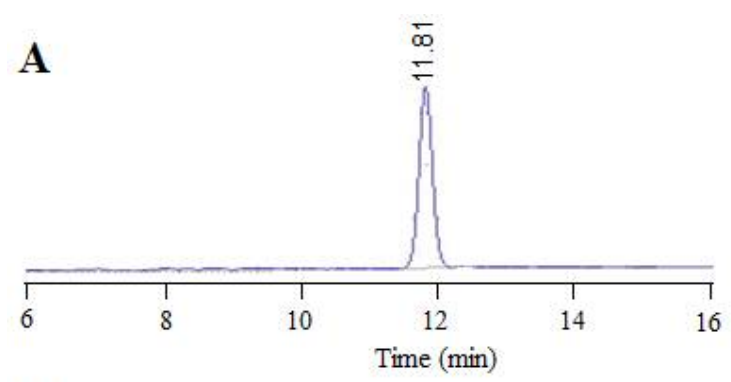

$\mathbf{B}$
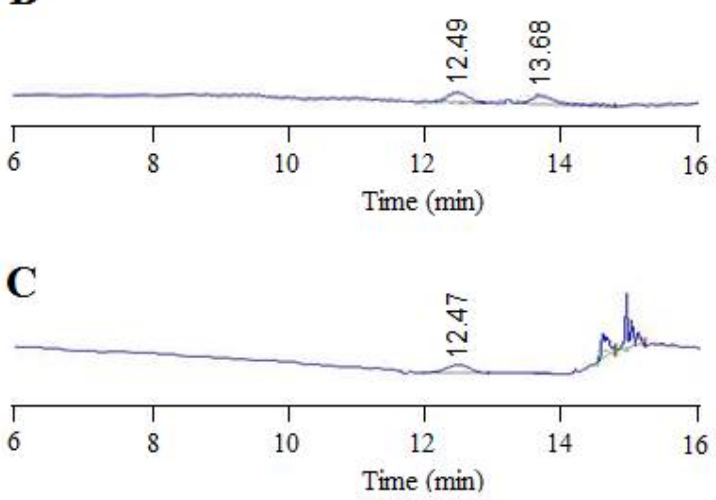

Figure 1: Chromatograms of serum PQ. (A) 100 $\mathrm{mg} / \mathrm{L} \mathrm{PQ}$ standard chromatograph. (B) $5 \mathrm{mg} / \mathrm{L}$ $P Q$ standard chromatograph. (C) Serum samples chromatograph of poisoning patient

Table 2: Oral intake of $P Q$ and serum $P Q$ of patients

\begin{tabular}{lccc}
\hline Group & Survival & Non-survival & $P$-value \\
\hline PQ quantity $(\mathrm{ml})$ & $23.58 \pm 26.23$ & $143.18 \pm 263.04^{\star \star}$ & 0.025 \\
PQ concentration $(\mathrm{mg} / \mathrm{l})$ & $2.07 \pm 0.67$ & $4.12 \pm 1.74^{\star *}$ & 0.000 \\
\hline
\end{tabular}

${ }^{\star *} P<0.01$, compared to the survival patients 
mRNA expressions of serum WISP1 genes

As can be seen from the Figure 2, mRNA expressions of WISP1 in serum were presented. The mRNA expressions of WISP1 in non-survival and survival groups at the first poisoned day were higher than those of health group $(p<0.01$, $p<0.01$ ) and mRNA expressions of WISP1 in survival group in the $3^{\text {rd }}$ day were downregulated compared with the NS group $(p<0.01$, $p<0.01)$.

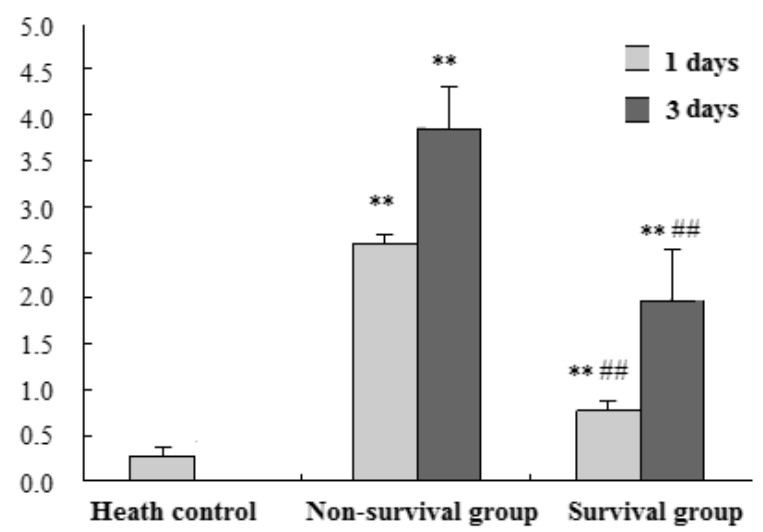

Figure 2: mRNA expression of WISP1 in different groups. RT-PCR assays were used to determine the mRNA levels of WISP 1. Data are expressed as the mean \pm SD. ${ }^{* *} p<0.01$ compared with health control group; \#\#p $<0.01$ compared with the non-survival group

\section{Serum WISP1 protein level}

WISP1 serum concentrations are presented in Figure 3. WISP1 protein serum concentration of the non-survivor group on the first day of poisoning was higher than those of health control group $(p<0.01)$ and the survival group $(p<$ $0.01)$. Similar to the first day, WISP1 protein serum levels of the non-survivor group on the third day of poisoning day were also higher than those of healthy control $(p<0.01)$ and survival group $(p<0.01)$. Besides, WISP1 protein levels in survival group at the first poisoned day and $(p$ $<0.01)$ third poisoned day $(p<0.01)$ were higher than that in health control group.

\section{Relationship between serum PQ concentration and WISP1 expression}

As can be seen from Table 3, the results of correlation analysis showed that serum $P Q$ contents was closely correlated with the WISP1 gene expression on the first day of poisoning $(\mathrm{OR}=0.621, p<0.01)$. A correlation between the serum $P Q$ and the serum WISP1 concentrations also occurred on the first $(\mathrm{OR}=$ $0.596, p<0.01$ ) and third days of poisoning (OR $=0.447, p<0.01)$. No obvious relationship was found between serum PQ levels and WISP1 gene expression $(\mathrm{OR}=0.164, \mathrm{p}>0.05)$ on the third day of poisoning.

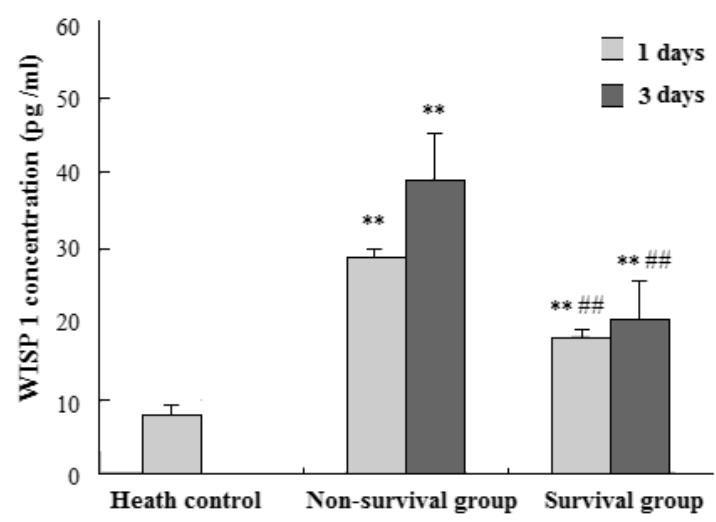

Figure 3: WISP1 concentrations in different groups. ELISA assays were used to determine WISP1 concentrations. Data are expressed as the mean $\pm \mathrm{SD} ;{ }^{* *} p<0.01$ compared with health control group; \#\#p<0.01 compared with the non-survival group

\section{Serum PQ concentration and prognosis}

Further, the relationship between $P Q$ concentrations and prognosis of $P Q$ intake patients was also analyzed by logistic regression analysis. The results showed that a higher serum $P Q$ concentration was closely correlated to higher mortality of $P Q$-poisoned patients $(\mathrm{OR}=$ $1.434, p<0.05)$.

Table 3: WISP1 protein concentrations in the serum of the three groups

\begin{tabular}{lcccccc}
\hline Group & Time & $\mathbf{n}$ & WISP $\mathbf{1}(\mathbf{p g} / \mathbf{m L})$ & $\boldsymbol{X}^{2}$ & F & $P$-value \\
\hline Control group & & 27 & $8.07 \pm 1.26$ & & & \\
Non-survival group & 1d & 11 & $28.76 \pm 3.93^{\star *}$ & 1125.46 & 250.12 & 0.000 \\
\multirow{2}{*}{ Survival group } & 3d & 9 & $39.02 \pm 9.72^{* * \# \#}$ & 2298.17 & 121.37 & 0.000 \\
& 1d & 26 & $18.02 \pm 1.08^{\star *}$ & & & \\
& 3d & 26 & $20.44 \pm 1.01^{\star *} \# \#$ & & &
\end{tabular}

Data are expressed as mean $\pm \mathrm{SD} ;{ }^{* *} p<0.01$ compared with health control group; \#\#p<0.01 compared with the non-survival group 


\section{DISCUSSION}

$P Q$ poisoning often result in death within a few days due to multiple organ failure (MOF), especially kidney and lung which are the target organs most affected. It has been reported that most of the survivors suffer from complicated pulmonary fibrosis (PF). In the study, $37 \mathrm{PQ}$ poisoned patients were investigated, and the mortality rate was $29.73 \%$. The early symptom of $P Q$ poisoning is alveolitis, as the lungs show alveolar collapse and inflammatory cells infiltrate into alveolar airspaces [11,12]. A previous report using $99 \mathrm{mTc}$ diethylenetriamine pentaacetate (DTPA) radioaerosol lung scintigraphy revealed that alveolar permeability is increased in PQpoisoned patients [13]. Lung alveolitis reduces lung volume and lung compliance, and in the late stage of $P Q$ intoxication, pulmonary fibrosis and respiratory failure is induced, finally leading to the death of PQ-poisoned patients. In this study, nine $P Q$ poisoned patients were finally died from acute respiratory failure.

It is estimated that the lethal dose of $P Q$ in an adult human is about $30 \mathrm{mg} / \mathrm{kg}[14,15]$ or $3-6 \mathrm{~g}$ of $P Q$ ion $[16,17]$. A previous report showed that ingestion of $>30 \mathrm{~mL}$ may lead to a fatal outcome in $P Q$-poisoned patients [18]. It was observed that patients with higher serum $P Q$ concentration led to higher mortality.

WISP1 is a secreted matricellular protein, which belongs to the CCN family. In humans, WISP1 is expressed in various organs, including the lung, heart, pancreas, kidney, placenta, small intestine, and spleen, etc [19]. Changes in WISP1 expressions in PQ-poisoned patients remain unknown. It is reported that $P Q$ can induce increase in TGF- $\beta 1$ and TNF- $\alpha$ in PQ poisoned patients and animals [20-24]. Longterm low-dose PQ exposure can induce EMT-like cellular transformation and subsequent fibrogenesis in A549 and human bronchial epithelial cells. It has also been reported that TGF- $\beta 1$ plays an important role in EMT-like cellular response and subsequent fibrogenesis of $P Q$ induced pulmonary cells [25]. WISP1 was increased in alveolar epithelial type II cells with stretch-induced EMT [8]. TGF- $\beta 1$ and TNF- $\alpha$ induced WISP1 in primary human lung fibroblasts, WISP1 exerts its profibrotic effects through IL-6-dependent induction of fibroblast proliferation [26]. The results revealed that both mRNA and protein levels of WISP1 were highly elevated in $\mathrm{PQ}$-poisoned patients, and that the expressions and serum contents of WISP1 in non-surviving patients were higher than those of surviving patients. In addition, serum PQ concentration was closely correlated with expression and serum concentration of WISP1 in PQ-poisoned patients.

\section{CONCLUSION}

WISP1 is up-regulated in PQ-poisoned patients, and serum $\mathrm{PQ}$ concentration is closely correlated with WISP1 expression. Furthermore, determination of serum PQ concentration and WISP 1 would be beneficial for forecasting the prognosis of $P Q$ poisoned patients.

\section{DECLARATIONS}

\section{Acknowledgement}

This work was supported by Medicine and health care in Shandong province science and technology development plan project of China (project no. 2011HW021). The authors would like to acknowledge Dr He Fang, the section chief of Hospital, and Dr. Su Quanping, the Manager of Center Laboratory of Hospital who provided the required information and data for performing this research project.

\section{Conflict of Interest}

No conflict of interest associated with this work.

\section{Contribution of Authors}

The authors declare that this work was done by the authors named in this article and all liabilities pertaining to claims relating to the content of this article will be borne by them.

\section{Open Access}

This is an Open Access article that uses a funding model which does not charge readers or their institutions for access and distributed under the terms of the Creative Commons Attribution License (http://creativecommons.org/licenses/by 14.0) and the Budapest Open Access Initiative (http://www.budapestopenaccessinitiative.org/rea d), which permit unrestricted use, distribution, and reproduction in any medium, provided the original work is properly credited.

\section{REFERENCES}

1. Klein-Schwartz W, Smith GS. Agricultural and horticultural chemical poisonings: mortality and morbidity in the United.2 States. Ann Emerg Med 1997; 29: 232-238.

2. Liu JY, Li LR, Jin HY, Wang GF. Influence factors for prognosis in patients with acute oral poisoning with 
paraquat. Zhonghua Lao Dong Wei Sheng Zhi Ye Bing Za Zhi 2012; 30(9): 686-687.

3. Ma ZX, Wang WSh, Lu QL, Liu HX, Meng J, Ren Y, Zhang X, Liu HD. Clinical analysis of 106 cases of acute $P Q$ poisoning. Chin J Industr Hygiene Occup Dis 2009; 27(8): 493-494.

4. Babic AM, Kireeva ML, Kolesnikova TV, Lau LF. CYR61, a product of a growth factor-inducible immediate early gene, promotes angiogenesis and tumor growth. Proc Natl Acad Sci USA 1998; 95: 6355-6360.

5. Jun Jl, Lau LF. Taking aim at the extracellular matrix: CCN proteins as emerging therapeutic targets. Nat Rev Drug Discov 2011; 10(12): 945-963.

6. Lau LF. CCN1/CYR61: the very model of a modern matricellular protein. Cell Mol Life Sci 2011; 68(19): 3149-3163.

7. Königshoff $M$, Kramer $M$, Balsara N, Wilhelm J, Amarie OV, Jahn A, Rose F, Fink $L$, Seeger $W$, Schaefer $L$, Günther A, Eickelberg O. WNT1-inducible signaling protein-1 mediates pulmonary fibrosis in mice and is upregulated in humans with idiopathic pulmonary fibrosis. J Clin Invest 2009; 119(4): 772-787.

8. Heise RL, Stober V, Cheluvaraju C, Hollingsworth JW, Garantziotis S. Mechanical stretch induces epithelialmesenchymal transition in alveolar epithelia via hyaluronan activation of innate immunity. $\mathrm{J}$ Biol Che 2011; 286(20): 17435-17444.

9. Anonymous. WMA Declaration of Helsinki - Ethical Principles for Medical Research Involving Human Subjects.

http://www.wma.net/en/30publications/10policies/b3/.

10. Li HH, Li Q, Liu P, Liu Y, Li J, Wasserloos K, Chao W, You M, Oury TD, Chhinder S, Hackam DJ, Billiar TR, Leikauf GD, Pitt BR, Zhang LM. WNT1-inducible signaling pathway protein 1 contributes to ventilatorinduced lung injury. Am J Respir Cell Mol Biol 2012; 47(4): 528-535.

11. Hong SY, Yang DH, Hwang KY. Associations between laboratory parameters and outcome of $P Q$ poisoning. Toxicol Lett 2000; 118(1-2): 53-59.

12. Fukuda Y, Ferrans VJ, Schoenberger Cl, Rennard SI, Crystal RG. Patterns of pulmonary structural remodeling after experimental $P Q$ toxicity: the morphogenesis of intraalveolar fibrosis. Am J Pathol 1985; 118(3): 452475.

13. Kao CH, Hsieh JF, Ho YJ, Hung DZ, Lin TJ, Ding HJ. Acute $P Q$ intoxication: using nuclear outcome pulmonary studies to predict patient. Chest 1999; 116(3): 709-714.

14. Liu P, He YZ, Wang HC. Study on the prognosis of patients with acute $P Q$ intoxication. Zhonghua Lao Dong Wei Sheng Zhi Ye Bing Za Zhi 2011; 29(3): 212-215.
15. Yoon SC. Clinical outcome of $P Q$ poisoning. Korean $J$ intern Med 2009; 24(2): 93-94.

16. Pavan M. Acute kidney injury following $P Q$ poisoning in India. Iran J kidney Dis 2013; 7(1): 64-66.

17. Kolilekes L, Ghizopoulou E, Retsou S, Amaro A, Remião $F$, Bastos ML, Carvalho F. Severe $P Q$ poisoning: a longterm survivor. Respiratory Medicine Extra 2006; 2: 6770.

18. Delirrad M, Majidi M, Boushehri B. Clinical features and prognosis of $P Q$ poisoning: a review of 41 cases. Int $J$ Clin Exp Med 2015; 8(5): 8122-8128.

19. Pennica D, Swanson TA, Welsh JW, Roy MA, Lawrence $D A$, Lee J, Brush J, Taneyhill LA, Deuel B, Lew M, Watanabe $C$, Cohen RL. WISP genes are members of the connective tissue growth factor family that are upregulated in Wnt-1-transformed cells and aberrantly expressed in human colon tumors. Proc Natl Acad Sci USA 1998; 95(25): 14717-14722.

20. Zheng $X$, Sun $X$, Ma $P$, Liu Z, Jiang N. Therapeutic potential of intravenous Xuebijing on transforming growth factor $\beta 1$ and procollagen type III peptide in patients with acute $P Q$ poisoning. J Tradit Chin Med 2012; 32(4): 584-589.

21. Zhang $Z$, Ding L, Wu L, $X u$ L, Zheng L, Huang $X$. Salidroside alleviates $P Q$-induced rat acute lung injury by repressing TGF- $\beta 1$ expression. Int J Clin Exp Pathol 2014; 7(12): 8841-8847.

22. Liu H, Ding $Y$, Hou $Y$, Zhao G, Lu $Y$, Chen $X$, Cai $Q$, Hong G, Qiu $Q$, Lu Z. The protective effect of bone marrow mesenchymal stem cells carrying antioxidant gene superoxide dismutase on $P Q$ lung injury in mice. Zhonghua Lao Dong Wei Sheng Zhi Ye Bing Za Zhi 2016; 34(1): 1-7.

23. Liu W, Shan LP, Dong XS, Liu Z. Toll-like receptor 4 implicated in acute lung injury induced by $P Q$ poisoning in mice. Int J Clin Exp Med 2014; 7(10): 3392-3397.

24. Jiang $L$, Zhang $Y$, Sun $Y, H u L$, Gao D. Artesunate attenuates lung injury in $P Q$-intoxicated rats via downregulation of inflammatory cytokines. Clin Lab 2015; 61(11): 1601-1607.

25. Yamada A, Aki T, Unuma K, Funakoshi T, Uemura $K$. Paraquat induces epithelial-mesenchymal transition-like cellular response resulting in fibrogenesis and the prevention of apoptosis in human pulmonary epithelial cells. PLOS ONE 2015; 10(3): e0120192.

26. Klee $S$, Lehmann $M$, Wagner DE, Baarsma $H A$, Königshoff $M$. WISP1 mediates IL-6-dependent proliferation in primary human lung fibroblasts. Sci Rep 2016; 6: 20547. 